\title{
Application of epoxy functional silanes in the preparation of DNA microarrays
}

\author{
EMILIA FRYDRYCH-TOMCZAK ${ }^{1}$, BARBARA USZCZYŃSKA ${ }^{2}$, TOMASZ RATAJCZAK ${ }^{3}$, WOJCIECH T. MARKIEWICZ ${ }^{3}$, \\ Marek Figlerowicz ${ }^{2,4}$, MareK Nowicki ${ }^{5}$, Hieronim MaCieJeWShi ${ }^{1,6}$, MarCin K. ChMielewSKi ${ }^{3 *}$ \\ ${ }^{1}$ Poznan Science and Technology Park, A. Mickiewicz University Foundation, Poznań, Poland \\ ${ }^{2}$ Laboratory of Molecular and Systems Biology, Institute of Bioorganic Chemistry, PAS, Poznań, Poland \\ ${ }^{3}$ Laboratory of Bioconjugate Chemistry, Institute of Bioorganic Chemistry, PAS, Poznań, Poland \\ ${ }^{4}$ European Center for Bioinformatics and Genomics, Poznan University of Technology, Poznań, Poland \\ ${ }^{5}$ Faculty of Technical Physics, Poznan University of Technology, Poznań, Poland \\ ${ }^{6}$ Faculty of Chemistry, A. Mickiewicz University, Poznań, Poland \\ *Corresponding author: maro@ibch.poznan.pl
}

\begin{abstract}
Nucleic acid microarrays have recently become one of the basic techniques in the study of gene expression. Owing to progress in the field of miniaturization, thousands of oligonucleotides differing in terms of their sequences can be systematically placed on a small area of a solid support (usually glass). These probes are capable of simultaneously interacting with a large number of longer nucleic acids from particular genes. Nucleic acid microarray construction technology consists, primarily, of the appropriate functionalization of a glass surface with the use of organofunctional silanes. Oligonucleotides known as probes are attached to a functionalized surface using, for instance, the lithography technique and, after being linked to the surface, they are subjected to hybridization with complementary and labelled fragments of nucleic acids known as samples of unknown sequences. In this paper, we present a method for constructing DNA microarrays that is based on the use of microscopic slides modified with epoxy functional group-containing silanes. This study was aimed at optimizing the production of DNA microarrays. The study tested the usefulness of four different epoxy functional silanes with one or three alkoxy groups. In addition, slides were silanized with the use of alkylsilane. The glass slides were characterized using a goniometer and an atomic force microscope (AFM). The synthesized amino linker-containing oligonucleotide probes were printed onto the glass slides in order to check the effectiveness of their attachment to the solid surface.
\end{abstract}

Key words: DNA microarrays, organofunctional silanes, glass supports, oligonucleotides

\section{Introduction}

Microarray analyses are among the basic techniques available in modern molecular biology. They are used, inter alia, to conduct research into gene expression profiles, DNA and RNA sequencing, the organization of genomes (Fodor at al., 1991; Fodor et al., 1993), and the secondary and tertiary structures of nucleic acids (Kierzek and Fratczak, 2008). Most importantly, they provide a possibility for the simultaneous analysis of a large number of different molecules of DNA or RNA isolated from small amounts of biological material. The application of microarrays in the field of medical analytics has considerably shortened the diagnostic process and enhanced the credibility of its results. Moreover, it has created a rationale for the introduction of individualized therapy (Kordek and Bednarek, 2005). In biology, the term microarrays was originally used for small plates (usually made of glass) with DNA molecules attached to their surfaces in a systematic manner (Venkatasubbarao, 2004; Trevino et al., 2007). Currently, any collection of biomolecules, cells or tissues immobilized on a solid support in a strictly defined order is called a microarray. The role of the solid support can be played by flat surfaces (plates) as well as spherical ones (beads). Among the biomolecules attached to solid surfaces are not only DNA/RNA oligonucleotides and products of the polymerization chain reaction (PCR), but also peptides, proteins (e.g. immunoglobulins, receptor proteins), lipids, 
and even carbohydrates (Zhang et al., 2004; Simon, 2004; Blalock, 2003; Hardiman, 2003; Baldi and Hatfield 2002). In the case of DNA microarrays, a collection of shorter or longer molecules called probes is attached to the surface (Venkatasubbarao, 2004; Trevino et al., 2007). Each probe is, as a rule, complementary to one of the many DNA molecules potentially capable of being present in the examined sample. At present, DNA microarrays containing as many as 6 million probes per $1 \mathrm{~cm}^{2}$ are available (Gershon, 2005). As a result, it is possible to analyze the expression of a vast number of genes during one experiment, using only small amounts of biological material.

The most frequently used supports in the production of microarrays are glass slides which are characterized by the non-porous nature of their surfaces, their stability at elevated temperatures, excellent optical properties, low fluorescence in the wave range used during microarray analysis, considerable ability to be chemically modified, easy availability and low cost. They are versatile; and therefore, products of the polymerization chain reaction (product, product), as well as synthetic nucleotides of different lengths, can be printed on the glass slides (Chiu, 2003).

Immobilization of biomolecules consists of their being linked to a glass surface modified with organofunctional silane. Functional groups introduced via silanization make it possible to bind biomolecules to the solid support by means of electrostatic or covalent interactions (Henke and Krull, 1999; Uszczyńska et al., 2012). The linkers that are most frequently used in the manufacture of DNA microarrays are epoxy functional silanes of the general formula $\mathrm{Z}\left(\mathrm{CH}_{2}\right)_{\mathrm{n}} \mathrm{Si}(\mathrm{OR})_{3}$, where $\mathrm{R}$ represents $\mathrm{CH}_{3}, \mathrm{C}_{2} \mathrm{H}_{5}, \mathrm{C}_{2} \mathrm{H}_{4} \mathrm{OCH}_{3}$, and $\mathrm{Z}$ is an epoxy functional group (Maciejewski et al., 2004; Marciniec et al., 2011; Marciniec, 2002). These silanes are successfully applied to bind biomolecules to solid supports thanks to the presence of an epoxy ring in their structure that reacts with many nucleophilic compounds, such as amines, thiols, alcohols and acids (Wong at al., 2005). The most frequently applied silane is 3-glycidoxypropyltrimethoxysilane (Fiedorow et al., 2008), as it provides good reproducibility of support modification and enables attaching oligonucleotide probes in high density. (Piehler et al., 2000; Cloarec et al., 2002). On the other hand, the epoxycyclohexyl group (e.g. 2-(3,4-epoxycyclohexyl)ethyltrimethoxysilane) is more reactive than the glycidyl group and easily reacts with nucleophilic agents under the influence of thermal or chemical initiation, such as those cross-linked with amines.

Growing demand for synthetic DNA/RNA fragments has resulted in the development of several methods for the synthesis of fragments of nucleic acids. However, only two have been applied on a commercial scale, namely the phosphoramidite method (Beaucage and Caruthers, 1981; Beaucage and Iyer, 1992) and, more seldom, the H-phosphonate method (Froehler et al., 1986; Garegg et al., 1985). Both methods allow synthesis of nucleic acids on solid supports, which considerably facilitates the process of product purification. Moreover, the process may be fully automated, which results in the production of the longer fragments of DNA that are found in microarrays.

The many practical applications of DNA microarrays in various areas of biotechnology have brought about considerable progress in scientific research. In consequence, most of the methods developed for the manufacture of microarrays are under patent protection, which results in the necessity of purchasing expensive licenses, or potential users having to pay higher prices for the product. Taking the above into account, we have constructed and synthesized microarrays based on our own solutions in order to reduce the final cost.

\section{Material and methods}

\section{Cleaning and silanization of glass supports}

In our studies, microarray supports were microscopic slides cleaned by rinsing with an aqueous solution of Trilux detergent (Analab) and distilled water, followed by drying in an inert gas atmosphere. Cleaned microscope glass slides were incubated for one hour in an appropriate epoxy silane solution in toluene in an ultrasonic bath. Monoalkoxysilanes (3-glycidoxypropyldimethylethoxysilane $(\mathrm{Gm}), 2$-(3,4-epoxycyclohexyl)-ethyldimethylethoxysilane $(\mathrm{Cm})$ ) and trialkoxysilanes (3-glycidoxypropyltrimethoxysilane (Gt), 2-(3,4-epoxycyclohexyl) ethyltrimethoxysilane $(\mathrm{Ct}))$ (Fig. 1) were used in three different concentrations $(0.02 \% ; 0.2 \%$ and $2 \%)$.

Silanization of slides with monoalkoxysilanes in the presence of butyltrimethoxysilane (BMS) (1:1) (Pohl et al., 1986; Luderer and Walschus, 2005) was additionally performed at a concentration of $0.2 \%$. After silanization, the slides were washed with toluene and heated at $110^{\circ} \mathrm{C}$ for 1 hour in order to form a covalent bond be- 
<smiles></smiles>

$\mathrm{Gt}$<smiles>CO[Si](C)(C)CCCOCC1CO1</smiles>

$\mathrm{Gm}$<smiles>CO[Si](C)(C)CCC1CCC2OC2C1</smiles>

$\mathrm{Cm}$

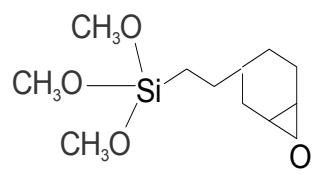

$\mathrm{Ct}$

Fig. 1. Structures of epoxy functional silanes used in the experiments

tween the silane and the glass support. Then, the slides were cooled down, washed with ethanol to remove any residue of unbound silane and dried using a microcentrifuge for slides, followed by drying in a nitrogen atmosphere.

To evaluate the quality of the surfaces of slides before and after silanization, the static contact angle was measured using a Kruss DSA 100 goniometer. Ultrapure water of a resistivity of $18 \mathrm{M} \Omega \cdot \mathrm{cm}$ was used for the measurement (miliQ $\mathrm{H}_{2} \mathrm{O}$ ). Droplet size was $3 \mu \mathrm{l}$ in each case and the contact angle was read immediately after adding a droplet. Moreover, the slides were characterized using an atomic force microscope. Micrographs were taken in air on a NanoSurf easyScan2 microscope in intermittent contact mode using a Nanosensors microcantilever (model PPP-NCLR). Image processing was performed with the WSXM program (Horcas at al., 2007).

\section{Synthesis of oligonucleotides with amino linkers}

Nucleic acid fragments were synthesized using the phosphoramidite approach with an automatic DNA/RNA synthesizer.

The method consists of the multiple repetition of four steps (detritylation, coupling, blocking and oxidation) resulting in the growth of a nucleic acid chain. The duration of each step is given in Table 1 .

Table 1. Duration of the steps used in the oligonucleotide synthesis using the phosphoramidite approach

\begin{tabular}{l|c}
\hline \multicolumn{1}{c|}{ Step } & Time (s) \\
\hline Detritylation & 35 \\
\hline Coupling & 60 \\
\hline Blocking & 25 \\
\hline Oxidation & 150 \\
\hline
\end{tabular}

The obtained oligonucleotides are bound to an epoxy support that must be equipped with an amine linker. In the last step of this oligonucleotide synthesis, the phosphoramidite of the amine linkers was used according to the scheme shown below (Fig. 2). Thus, the amine linkers were bound to the $5^{\prime}$-hydroxyl group of the nucleotide via the phosphate diester bond.

Syntheses of the 5-aminopenthyl and 6-aminohexyl linkers proceeded in three steps. In the first step, the amino group was selectively blocked in the presence of a free hydroxyl group with the use of fluorenylmethoxycarbonylchloride (Fmoc-Cl). In the case of 5- $N$-(Fmoc)aminopenthanol synthesis, this reaction was conducted at room temperature for $21 \mathrm{~h}$ in a mixture of acetone, MiliQ water and a saturated solution of $\mathrm{Na}_{2} \mathrm{CO}_{3}(18 / 10 / 2 \mathrm{v} / \mathrm{v} / \mathrm{v})$ (Lin et al., 1998; Guo et al., 1994; Khandazhinskaya et al., 2005). Afterwards, the product was threefold extracted in a mixture of $\mathrm{H}_{2} \mathrm{O}$ /methylene chloride and chromatographically purified with the use of methanol/methylene chloride as eluent. The product was obtained with a $67.7 \%$ yield. The same procedure was used to obtain and purify $6-\mathrm{N}$-(Fmoc)aminohexanol with a $71.4 \%$ yield. Thus, the obtained products, $5-N$-(Fmoc)aminopenthanol and 6- $N$-(Fmoc)aminohexanol, were converted into phosphoramidite derivatives via the addition of 2-cyanoethyl$N, N$-diisopropylphosphoramidite and $1 H$-tetrazole as activator. The reactions were conducted in dry methylene chloride for $2 \mathrm{~h}$ at room temperature. After chromatographic purification in a mixture of $\mathrm{DCM} / \mathrm{n}$-hexan/disopropylethylamine $(4 / 6 / 0.2 \mathrm{v} / \mathrm{v} / \mathrm{v})$, products were obtained with $65.1 \%$ and $46.5 \%$ yield, respectively. The phosphoramidite derivatives were next dissolved in acetonitrile and used as standard nucleoside phosphoramidites to bind them on a solid support to the free $5^{\prime}$-hydroxyl group of the nucleotide. The fluorenylmethoxycarbonyl group is compatible with the protective groups of nucleotides and, in the last step of unblocking, undergoes a $\beta$-elimination reaction with the use of a concentrated ammonia solution. Syntheses of twenty 70-mer oligonucleotide chains with 5-aminopenthyl and 6-aminohexyl amino linkers at the $5^{\prime}$ terminus and a 9-mer oligonucleotide combinatorial library, labelled with Quasar670 fluorescence dye (MIX-Q), were performed using an automatic synthesizer on a 0.2 mole scale. MIX-Q was 


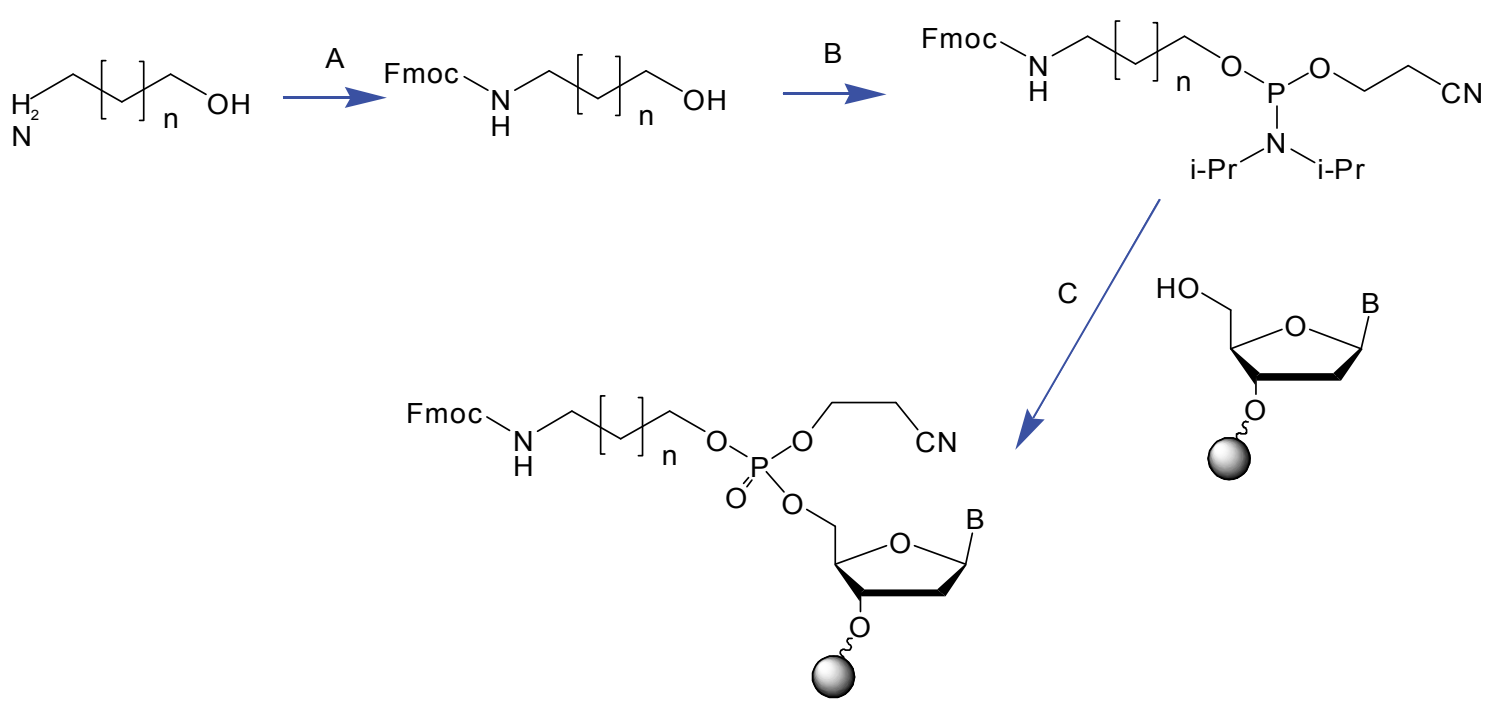

Fig. 2. Synthesis and binding of amino linkers (where $\mathrm{n}=3,4$ ) to $5^{\prime}$-hydroxyl group of oligonucleotide on a solid support. A) Fmoc-Cl, $\mathrm{H}_{2} \mathrm{O}$ :acetone, $\mathrm{Na}_{2} \mathrm{CO}_{3}$, B) 2-cyanoethyl- $N, N$-diisopropylphosphoramidite, $1 H$-tetrazole, C) i - $1 H$-tetrazole, ii $-\mathrm{I}_{2} /$ pyridine $/ \mathrm{H}_{2} \mathrm{O}$

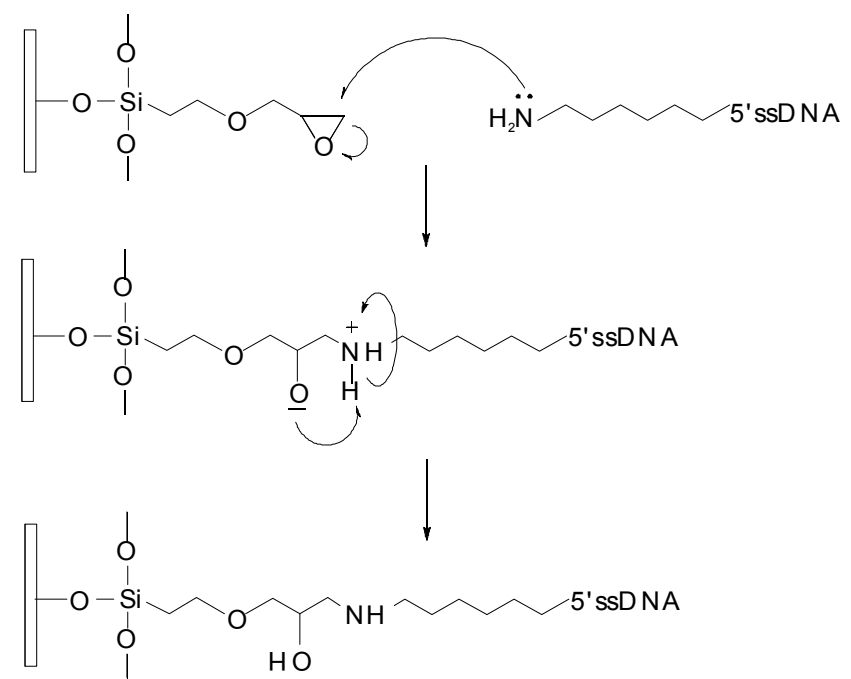

Fig. 3. Binding of oligonucleotides to a support modified with epoxy functional silane

synthesized in the procedure mentioned above, but the mixture of four deoxynucleoside phosphoramidites was prepared in a mixing chamber before passing it by the column filled with the solid support. Thus, the obtained 9-mer oligonucleotide combinatorial library was labelled at the $5^{\prime}$ terminus with a commercial phosphoramidite of Quasar670 (Biosearch Technologies). After performing the syntheses, supports with modified oligonucleotides were immersed in a concentrated ammonia solution $\left(12 \mathrm{~h}\right.$ at $\left.55^{\circ} \mathrm{C}\right)$ to remove protective groups and separate oligonucleotide chains from the supports. In the subsequent step, oligonucleotides were desalted on Se- phadex NAP 25 columns followed by lyophilization. Thus, synthesized oligonucleotides with amino linkers were dissolved in a printing buffer and printed on glass slides bearing epoxy groups to be covalently bound to the surface (Fig. 3).

\section{Immobilization of oligonucleotides on a support contai- ning epoxy groups on its surface}

The experiments involved the preparation of three types of microarrays using three different sets of probes: 20 probes corresponding to the heat shock protein genes of Arabidopsis thaliana (Amino-C6 70-mers, Operon), 20 probes corresponding to the heat shock protein genes of Arabidopsis thaliana (Amino-C5 70-mers, IBCH, PAS) and 20 probes corresponding to the chloroplast DNA of Cucumis sativus (Amino-C6 70-mers, Operon). The probes in the Epoxide Spotting Buffer (IDT) were spotted onto epoxide-coated slides in three different concentrations: 10,25 and $40 \mu \mathrm{M}$ using a NanoPrint arrayer (Arrayit), with a 4-pins-in-row pin configuration. Each probe concentration was spotted three times. The microarray spotting process was performed at room temperature and at a humidity of $55 \%$.

The spotting pattern was identical for each probe set and involved the formation of 4 identical blocks of probes, 600 probes in each ( 10 columns $\times 60$ rows of probes).

Both DNA probe sets, for Arabidopsis thaliana and Cucumis sativus, were investigated with the mfold program (Zuker, 2003) and the results suggest that these 
sequences do not form strong secondary structures and are good candidates for microarray experiments.

\section{Hybridization of a 9-mer oligonucleotide combinatorial library}

Silanized and spotted slides were immersed in a microarray wash station (Arrayit) filled with $500 \mathrm{ml}$ of a 1\% aqueous solution of dodecyl sulfate (SDS) and incubated for 1 minute at room temperature. Next, the slides were transferred into a wash station filled with $500 \mathrm{ml} \mathrm{H}_{2} \mathrm{O}$ miliQ at a temperature $90-100^{\circ} \mathrm{C}$. After a 30 -second incubation in hot water, the slides were dried with the use of a microarray centrifuge (Arrayit). Next, the dried slides were covered with a hybridization mixture containing complementary sequences labelled with a fluorescent marker (MIX-Q) and a SpotQC hybridization buffer (IDT). The hybridization mixture was incubated for $5 \mathrm{~min}$. at $80^{\circ} \mathrm{C}$ before being applied onto a slide. Hybridization was conducted for $30 \mathrm{~min}$. at $40^{\circ} \mathrm{C}$ in manual hybridization chambers (Corning $\AA$ ). After hybridization, microarrays were subjected to a series of rinsing operations performed via immersion in a wash station containing in turn: $2 \times \mathrm{SSC}$ (citric buffer) $+0.1 \% \mathrm{SDS}(500 \mathrm{ml})$, $0.5 \% \mathrm{SDS}(500 \mathrm{ml})$ and $0.05 \% \mathrm{SDS}(500 \mathrm{ml})$. All these rinsing operations were performed at room temperature. Then, the results were analyzed with the use of a Perkin Elmer microarray scanner (ScanArray Express) at a wavelength of $\lambda=633 \mathrm{~nm}$.

\section{Preparation of Arabidopsis thaliana plant material}

Arabidopsis thaliana plants, once grown for 30 days, were stressed before collection $\left(\mathrm{T}=40^{\circ} \mathrm{C}, \mathrm{t}=30 \mathrm{~min}\right)$. Plant leaves from the tested (temperature-treated) and control (untreated) group were collected and roughly ground in liquid nitrogen. The RNA was isolated from this plant material using an RNeasy Plant Mini Kit (Qiagen). DNA contamination was removed with a TURBO DNA-free ${ }^{\mathrm{TM}}$ apparatus (Ambion) according to the manufacturer's instructions. Next, the quality of the obtained RNA was investigated using a BioAnalyzer 2100 (Agilent Technologies Inc). Next, the reverse transcription reaction was performed using $15 \mu \mathrm{q}$ of RNA, which showed a quality of RIN $\geq 9$, and, as a result, the cDNA was obtained for each sample. The reverse transcription reaction was the first step of the indirect RNA labelling process performed using the SuperScript Indirect cDNA Labeling System (Qiagen). During the labelling process, cDNA of treated plants was labelled using $\mathrm{Cy} 5$ and cDNA from the control plants using Cy3. After labelling, the samples were purified using a MinElute Purification Kit (Qiagen) according to the manufacturer's instructions. The efficiency of the reverse transcription and the labelling process were investigated using a NanoDrop 1000 (ThermoScientific).

\section{Hybridization of Arabidopsis thaliana plant material}

Slides with immobilized probes for heat shock protein genes were placed in chambers for automatic hybridization of the hybridization station (TECAN, Hs4800). Next, the prehybridization step was performed by placing on the microarray surface $150 \mu \mathrm{l}$ of the hybridization buffer containing $20 \times \operatorname{SSC}(37.5 \mu \mathrm{l}), 10 \% \operatorname{SDS}(1.5 \mu \mathrm{l})$, $10 \mathrm{mg} / \mathrm{ml} \mathrm{BSA}(1.5 \mu \mathrm{l})$ and $\mathrm{H}_{2} \mathrm{O}$ Ambion $(109.5 \mu \mathrm{l})$. Before being used, the prehybridization buffer was heated to $\mathrm{T}=43^{\circ} \mathrm{C}$. After 45 minutes of prehybridization, the slide was washed with $0.05 \times \mathrm{SSC}$. The hybridization SlideHyb\#3 buffer (Ambion) was heated to $\mathrm{T}=$ $68-70^{\circ} \mathrm{C}$ and incubated at this temperature for 30 minutes. The labelled plant cDNA was pooled. One of the treated samples (Cy5) was mixed with one control sample (Cy3) and evaporated using speedvac (UNIEQUIP) to a volume below $10 \mu \mathrm{l}$. Next, $115 \mu \mathrm{l}$ of hybridization buffer $\left(\mathrm{T}=43^{\circ} \mathrm{C}\right)$ was added to each pair of samples. The samples were vortexed, centrifuged and placed on the microarray. Hybridization was performed at $\mathrm{T}=$ $42^{\circ} \mathrm{C}$ for $18 \mathrm{~h}$. Next, a set of washing steps in the hybridization station involved the following solutions: $2 \times \mathrm{SSC}$ $+0.1 \%$ SDS, $0.2 \times$ SSC i 0.05 SSC. Fluorescence was detected $(\lambda=633 \mathrm{~nm}$ and $\lambda=543 \mathrm{~nm})$ using a ScanArray Express microarray scanner (PerkinElmer).

\section{Scanning of DNA microarrays}

After hybridization, dried DNA microarrays were scanned using the ScanArray Express (PerkinElmer) using one $(\lambda=633 \mathrm{~nm})$ or two $(\lambda=633 \mathrm{~nm}$ and $\lambda=$ $543 \mathrm{~nm}$ ) wavelengths, depending on the experiment. The scanning process for each DNA microarray was performed at $5 \mu \mathrm{m}$ resolution. Both TIFF and JPG images were produced as a result of the scanning process. Due to the large size of each image $(19 \times 16 \mathrm{~cm})$ only fragments will be presented to show the results.

\section{Preparation of a solution of increased ionic strength and examination of the effectiveness of probe immobiliza- tion}

A solution of increased ionic strength was prepared by dissolving 5 tablets of a phosphate buffer of $\mathrm{pH} 7.4$ 
(Sigma-Aldrich) in $500 \mathrm{ml}$ of $\mathrm{H}_{2} \mathrm{O}$ milliQ (5.0 M). To confirm that the probe immobilization is the result of a covalent bond between the epoxide-coated support and the probe aminolinker, and not the result of electrostatic interactions, after scanning the slides were immersed in the phosphate buffer and incubated for $15 \mathrm{~min}$ at room temperature. This was followed by rinsing with a $0.05 \times \mathrm{SSC}$ solution and drying by centrifugation in a High-Speed Centrifuge (ArrayIt). The results were analyzed with the use of a microarray scanner (ScanArray Express) at a wavelength of $\lambda=633 \mathrm{~nm}$ for DNA microarrays containing probes for Cucumis sativus or $\lambda=633$ and $\lambda=$ $543 \mathrm{~nm}$ for DNA microarrays containing probes for Arabidopsis thaliana.

\section{Results and discussion}

\section{Characterization of glass slides}

Before cleaning, the glass surfaces may contain different kinds of contaminations, such as organic or metal impurities and various particles which are fixed to the surface by weak electrostatic forces or by van der Waal's forces. The cleaning method resulted in the removal of contaminants without changing the topology of the surface of the glass slides; and consequently, the surface was activated to expose the high density of hydroxyl groups in the electrolyte. The modified slides were characterized using a goniometer and AFM. Goniometric analysis provides a relatively quick and simple means of assessing the cleanliness of a glass surface and the quality of glass slides after silanization. The results of contact angle measurements presented in Table 2 are the mean values of 8 measurements performed at different places on a slide. The contact angle measured after cleaning the slides was close to $0^{\circ} \mathrm{C}$, which indicates a highly hydrophilic surface, and thereby that the support had been efficiently cleaned. After silanization, the contact angle considerably increased, which suggests hydrophobization of the surface. The lowest contact angle values were found for slides covered with monoalkoxysilane. In the above-mentioned case, the poor coverage of glass resulted from an insufficient concentration of silane and the presence of only one alkoxy group, which was not sufficient to form a stable bond between the linker and the glass support. To increase the efficiency of the chemical immobilization of biomolecules on monoepoxysilane-treated glass surfaces, we performed additio- nal surface modification of the silanol groups with alkylsilanes. The contact angle obtained for glass slides silanized with monoalkoxysilane in the presence of butyltrimethoxysilane had slightly higher values than in the case of using only the monoalkoksysilane.

The highest contact angle values were found in the case of slides covered with trialkoxysilanes ( $\mathrm{Gt}, \mathrm{Ct}$ ). Trialkoxysilane molecules are good agents for glass surface modification, because they can bind strongly to a support through siloxane bonds and provide the desired surface properties or reactive groups through the choice of organic functionality. Contact angle values for 3-glycidoxypropyltrimethoxysilane are comparable with those reported by Luzinov $\left(52^{\circ} \mathrm{C}\right.$ ) (Luzinov et al., 2000), as well as by Wong, who observed the value of $55^{\circ} \mathrm{C}$ (Wong and Krull, 2005). The presence of three alkoxy groups makes it possible to form a stable bond between silane and the glass support. However, when high silane concentrations are applied, there is a risk during condensation with a solid support of the formation of multiple layers of silane or a possibility of the polymerization of unreacted silanol groups in the solution, leading to a reduction in the activity of the silane layer applied onto the support.

Changes in surface topology might additionally influence the contact angle results. Therefore, we monitored the contact angle and the topology changes by atomic force microscopy (AFM) of the samples. AFM is an extremely useful tool for studying modified surfaces, because it can provide real-space film morphology and nanostructure. It also provides detailed topographical information about surface features in terms of the roughness parameters of the films. Micrographs from AFM measurements (Fig. 4) show that the surfaces of the cleaned slides have flat surfaces without any major irregularities. On slides covered with epoxy functional silanes, an increased silane concentration results in the formation of agglomerates (called silane islands) on glass (Metwallib et al., 2006). This is accompanied by a rise in surface roughness $(\mathrm{Ra})$. The above phenomenon probably originates from the crosslinking of alkoxy groups unbound to glass support, which causes the formation of a heterogeneously modified layer.

\section{Immobilization and visualization of long DNA oligo- nucleotides onto epoxide-coated slides}

A general scheme for the production of DNA microarrays on supports modified with epoxy functional silane 
Table 2. Mean values of contact angles for slides covered with epoxy functional silanes

\begin{tabular}{l|c|c|c|c}
\hline \multicolumn{1}{c|}{ Silane } & $0.02 \%$ & $0.2 \%$ & $0.2 \%+\mathrm{BMS}$ & $2 \%$ \\
\hline $\mathrm{Gt}$ & $52.39 \pm 1.93$ & $52.62 \pm 1.23$ & - & $54.8 \pm 2.42$ \\
\hline $\mathrm{Gm}$ & $40.40 \pm 8.55$ & $45.90 \pm 6.47$ & $47.14 \pm 4.15$ & $48.16 \pm 8.12$ \\
\hline $\mathrm{Cm}$ & $41.07 \pm 9.37$ & $41.16 \pm 5.19$ & $45.82 \pm 3.95$ & $57.05 \pm 3.87$ \\
\hline $\mathrm{Ct}$ & $48.77 \pm 3.12$ & $54.97 \pm 2.26$ & - & $58.33 \pm 2.45$ \\
\hline
\end{tabular}

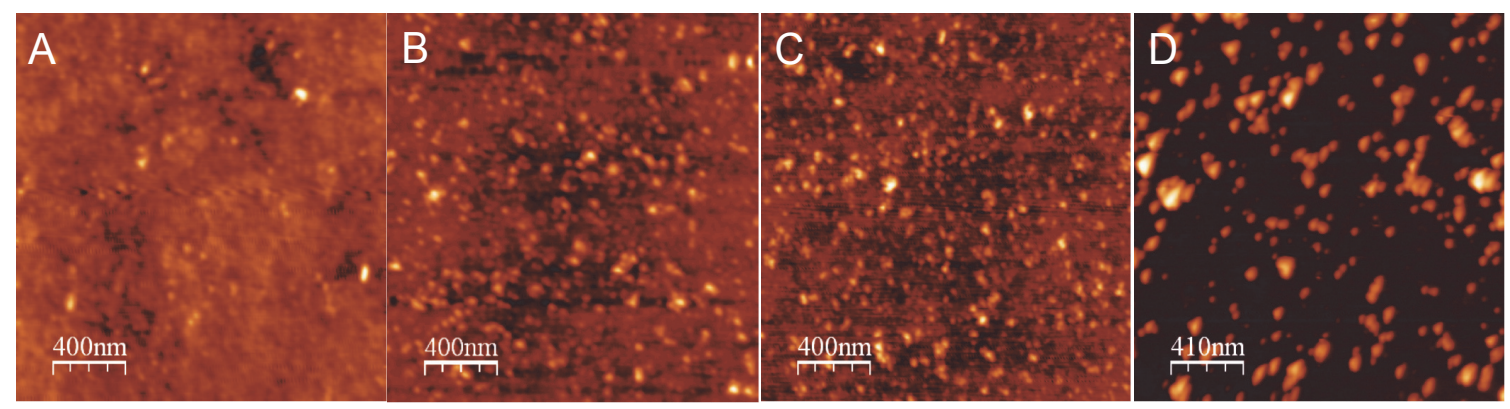

Fig. 4. Micrographs from AFM measurements of $A)$ an unmodified slide (Ra $=0.1 \mathrm{~nm})$, a slide covered with: $B) 0.2 \% \mathrm{Gt}$ $(\mathrm{Ra}=0.47 \mathrm{~nm}), \mathrm{C}) 0.2 \% \mathrm{Ct}(\mathrm{Ra}=0.48 \mathrm{~nm}), \mathrm{D}) 2 \% \mathrm{Gt}(\mathrm{Ra}=4.07 \mathrm{~nm})$

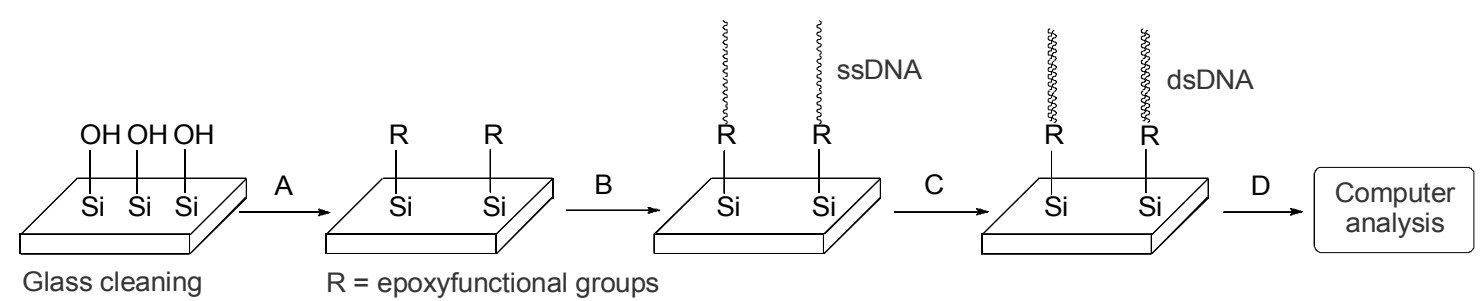

Fig. 5. Steps of DNA microarray production on epoxy functional supports; A - silanization, B - DNA immobilization, $\mathrm{C}$ - hybridization, $\mathrm{D}$ - detection

is shown in Figure 5. To investigate the effectiveness of the immobilization of probes onto epoxide-coated slides, a set of 20 probes corresponding to the chloroplast DNA of Cucumis sativus was spotted and hybridized with a combinatorial library labelled with fluorescent dye Quasar 670 (MIX-Q). The results of hybridization were visualized with the use of the ScanArray (Perkin Elmer) microarray scanner (Fig. 6). The results suggest that the immobilization proceeds effectively. The obtained DNA microarrays show very good morphology and a high intensity of the oligonucleotide binding sites in relation to the low intensities of the background. This was fully confirmed by the signal-to-noise ratio (SNR) that illustrates the ratio of the fluorescence signal to noise, and is calculated at the level of a quantitative image analysis
(GenePixPro 6.0, Molecular Devices). For the presented microarrays, the SNR parameter has a mean value in the range of 230-250.

\section{Investigation of the stability of $\mathrm{DNA}$ probe immobiliza- tion on epoxide-coated slides}

Next, the stability of probe immobilization was tested using a solution with increased ionic strength (Phosphate buffer $\mathrm{pH}=7.4,5.0 \mathrm{M}$ ). The absence of any probe leaching effect (Fig. 7C) for epoxide-coated slides indicated that the immobilization was permanent and was the result of covalent bond formation between slide epoxy groups and the probe aminolinker. Increased ionic strength removed all probes attached to the support using electrostatic interactions (Fig. 7D). 


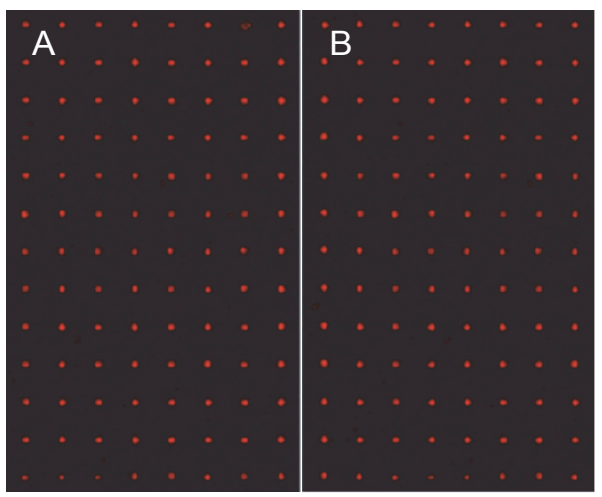

Fig. 6. Results of hybridization between 20 immobilized probes corresponding to the chloroplast DNA of Cucumis sativus and MIX-Q. Experiments were performed using slides prepared with a $0.2 \%$ solution of silane $\mathrm{Cm}+\mathrm{BMS}$ in toluene

A) mean SNR value: 242 ; B) mean SNR value: 249
Immobilization and visualization of long DNA oligonucleotides on epoxide-coated slides prepared with different concentrations of silane

Experiments involving the preparation of DNA microarrays with epoxysilanes at different concentrations were performed. The goal of this part of the research was to optimize the methods for the construction of DNA microarrays. The main focus were three solutions with different concentrations of silane: $2 \% \mathrm{v} / \mathrm{v}, 0.2 \%$ v/v, $0.02 \%$ v/v. Figure 8 presents example results obtained with three types of microarrays prepared using 3-glycidoxypropyltrimethoxysilane (at three different concentrations), 20 probes corresponding to the chloroplast DNA of Cucumis sativus and MIX-Q. The use of 3-glycidoxypropyltrimethoxysilane at concentrations of $2 \%$ and

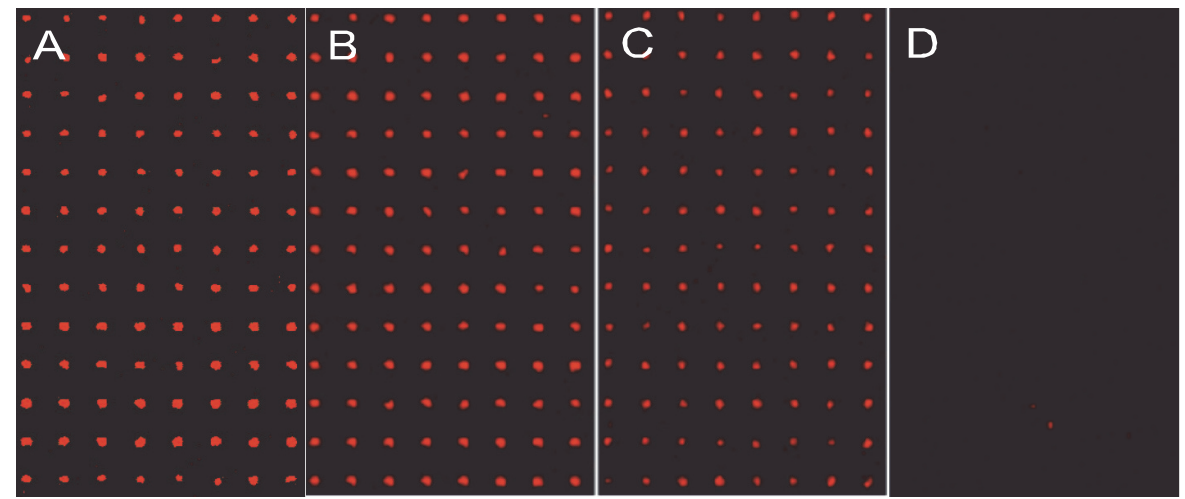

Fig. 7. A) Epoxy-coated slide with 20 probes corresponding to the chloroplast DNA of Cucumis sativus, mean SNR = 245; B) amine-coated slide (Corning $\left.{ }^{\circledR}\right)$ with 20 probes corresponding to the chloroplast DNA of Cucumis sativus, mean SNR value 243; C) slide presented in A after immersion in a solution with increased ionic strength; D) slide presented in B after immersion in a solution with increased ionic strength. The experiments were carried out on slides prepared using a $0.2 \%$ solution of silane $\mathrm{Cm}+\mathrm{BMS}$ in toluene

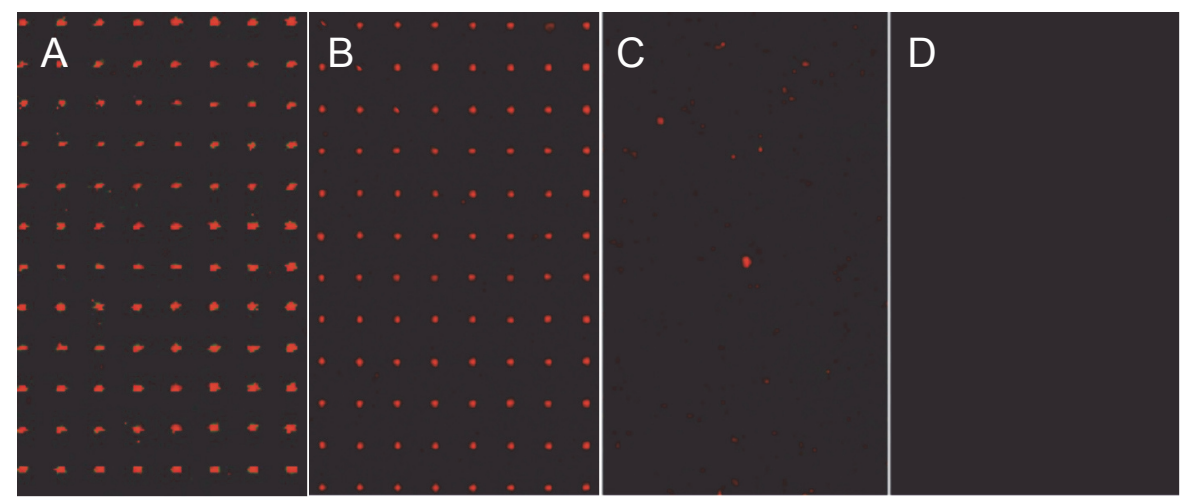

Fig. 8. Comparison of concentrations of silane Gt. The slide was prepared using silane solutions in toluene (v/v): A) $2 \%$, B) $0.2 \%$, C) $0.02 \%, D)$ immobilization of probes on a glass slide not covered with silane. Please note: elements present in panel C are just dust elements or not significant results of non-specific hybridization that were not fully removed after washing with solution with increased ionic strength 




Fig. 9. Visualization of immobilization of Arabidopsis thaliana probes. The slide was prepared using a $0.2 \% \mathrm{v} / \mathrm{v}$ solution of silane Gt in toluene. A) Fluorescence intensity for the labelled tested sample Cy5, mean SNR value 235; B) Fluorescence intensity for the labelled control sample Cy3, mean value 242 . Please note: differences in the probe intensity are caused by the different number of targets attached to different types of probes

$0.2 \%$ led to similar results (Fig. $8 \mathrm{~A}-\mathrm{B}$ ); whereas, at the concentration of $0.02 \%$, immobilization was not observed and no signal originating form hybridization was detected (Fig. 8C).

Experiments performed using 20 probes corresponding to the chloroplast DNA of Cucumis sativus and MIX-Q were undertaken to optimize methods for the construction of DNA microarrays with the application of epoxide supports, including the selection of optimal concentrations of silane. We decided to use probes corresponding to the chloroplast DNA of Cucumis sativus, because we have a high level of experience in working with this set of probes, which had been extensively tested during various experiments performed at the Institute of Bioorganic Chemistry, PAS (Zmieńko et al., 2011). The application of MIX-Q enabled a simple hybridization reaction to be performed in mild conditions $\left(\mathrm{T}=40^{\circ} \mathrm{C}\right)$, using chambers for manual hybridization (Corning ${ }^{\circledR}$ ). Such an approach helped to reduce the complexity of the microarray experiment through elimination of the steps required for RNA isolation and labelling from the biological material. Experiments involving the application of MIX-Q are much more repetitive than the microarray experiment with biological material. Moreover, combinatorial libraries containg labelled DNA fragments, such as MIX-Q, are extensively employed to investigate the quality of DNA microarrays before performing biological experiments, e.g SpotQC (IDT).

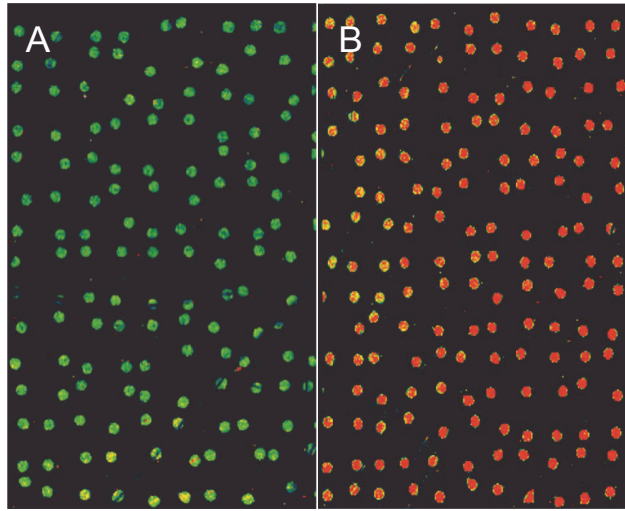

Fig. 10. Visualization of the immobilization of Arabidopsis thaliana probes. The slide was prepared using a $0.2 \% \mathrm{v} / \mathrm{v}$ solution of silane $\mathrm{Gm}$ in toluene. A) Fluorescence intensity for the labelled control sample Cy3, mean SNR value 241; B) fluorescence intensity for the sample Cy5 exposed to elevated temperature, mean SNR value 239. Please note: differences in the probe intensity are caused by the different number of targets attached to different types of probes

\section{Gene expression profiling in Arabidopsis thaliana under thermal shock conditions}

To investigate whether the DNA microarrays we developed can be employed in biological or biomedical research, experiments involving gene expression profiling in Arabidopsis thaliana under thermal shock conditions were performed. These experiments were designed to meet the requirements of a full microarray experiment, which consists of the isolation of biological material, the reaction of reverse transcription, labelling with two fluorescent dyes (Cy5-investigated sample plants exposed to thermal shock $\left(45^{\circ} \mathrm{C}, 30 \mathrm{~min}\right.$. incubation), Cy3-control sample - wild type plants), a prehybridization reaction, and an overnight hybridization reaction $\left(18 \mathrm{~h}\right.$ at $\left.45^{\circ} \mathrm{C}\right)$ to a DNA microarray containing 20 probes corresponding to Arabidopsis thalianagenes. The results we obtained are very close to those presented for probes corresponding to the chloroplast DNA of $\mathrm{CuCu}$ mis sativus and MIX-Q and fully confirm that the developed microarrays enable the permanent and effective immobilization of oligonucleotides of 70 nucleotides in length, also under conditions of elevated temperature (as high as $100^{\circ} \mathrm{C}$ ) - Figure 9 . Additionally, oligonucleotides of a relatively great length (70 nucleotides) are bound to the support in a way enabling hybridization of complementary sequences. Moreover, immobilization of probes to the support is optimized in a way which enables duplex formation during the hybridization reaction. 


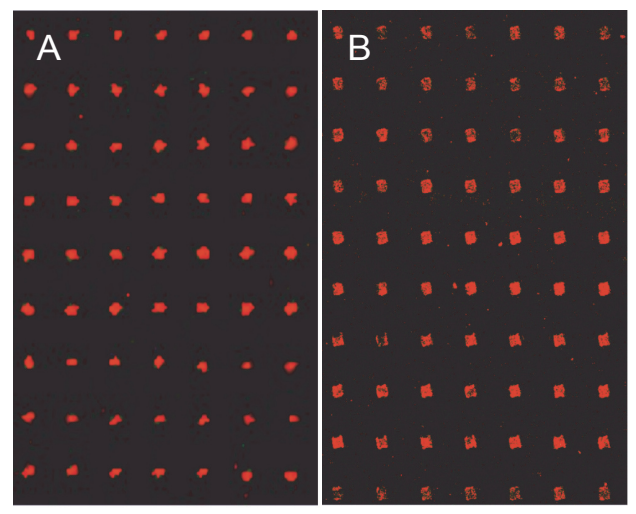

Fig. 11. Comparison of the immobilization of A) commercially available probes corresponding to the genes of the heat-shock proteins of Arabidopsis thaliana with an Amino-C6 linker, mean SNR value 248; B) probes corresponding to the genes of the heat-shock proteins of Arabidopsis thaliana synthesized in the Laboratory of Bioconjugate Chemistry, IBCH, PAS with an Amino-C5 linker, mean SNR value 244. Experiments were performed on slides prepared using a $0.2 \% \mathrm{v} / \mathrm{v}$ solution of silane $\mathrm{Ct}$ in toluene

The microarrays we developed enable immobilization of up to 20000 different types of probes (with a different sequence); this number is defined by the capacity of the NanoPrint arrayer (Arrayit) and may vary between available arrays. It is worth mentioning that the presented methods for slide surface modification enable the production of DNA microarrays which are compatible with most devices intended for experiments involving wholegenome DNA microarrays (except for Illumina and Affymetrix platforms). This makes them suitable for conventional biological experiments as well as for specific experiments which can be performed with the application of whole-genome DNA microarrays. In the case of silanization with monoalkoxysilane with no addition of alkyltrialkoxysilane, so-called "probe flowing" on the glass surface was observed as a result of nondurable silane binding to only one alkoxy group that made the silane layers unstable (Fig. 10).

\section{Immobilization and visualization of long DNA oligo- nucleotides with different types of aminoliker onto epo- xide-coated slides}

To verify the versatility of the DNA microarrays produced, experiments including commercially available oligonucleotide probes were performed. Two sets of probes were used: 20 , complementary to the genes of the heat-shock proteins of Arabidopsis thaliana, were purchased from Operon Technologies and 20 identical oligonucleotide fragments were obtained from the Laboratory of Bioconjugate Chemistry, Institute of Bioorganic Chemistry, Polish Academy of Sciences (IBCH, PAS). The probes differed only in terms of the kind of amino linker attached to the oligonucleotide at the synthesis stage. Probes synthesized by Operon Technologies contained a C6-Aminolinker, and probes synthesized at the IBCH, PAS were modified using a C5-Aminolinker. The results are characterized by an almost identical level of the fluorescence signal for both microarrays, and suggest that the developed construction method enables effective and permanent immobilization of probes to be performed with any amino linker (Fig. 11). In practice, this means that biological experiments with the use of the developed microarrays can be successfully conducted not only on the basis of commercially available probes, but also on the basis of probes synthesized in our own laboratory.

\section{Conclusions}

The best substrate for the production of microarray DNA were glass slides coated with an epoxyfunctional silane with three alkoxy groups ( $\mathrm{Ct}, \mathrm{Gt}$ ) and a concentration of at least $0.2 \%$. Monoalkoxysilanes $(\mathrm{Cm}, \mathrm{Gm})$ proved less efficient in binding to a solid support; however, if silanization is carried out in the presence of butyltrimethoxysilane, the microarrays generated look as good as those of trialkoxysilanes and have the same mean SNR value. The presented results have been reported for a patent application (Chmielewski et al., 2011), since the developed technology leads to good quality microarrays being obtained at relatively low financial outlays. This technology will significantly facilitate experiments and add to their flexibility. Moreover, the low cost of a single experiment enables experiments to be performed with a larger number of repetitions. This is of key importance in detecting even small differences between groups of organisms or samples under study at a molecular level. Furthermore, the increased number of repetitions results in a reduction in noise in the system, which directly translates into an increase in the statistical power of the experiment. The described DNA microarrays are characteristic of high values of the SNR parameter that reflects the ratio of signal-to-noise in- 
tensity. The application of such microarrays also permits a considerable simplification of the process of data analysis by, for instance, the elimination of the process of background correction.

\section{Acknowledgements}

This research has been supported by the Polish Ministry of Science and Higher Education grant no. N R12 002704.

\section{References}

Baldi P., Hatfield G.W. (2002) DNA Microarrays and Gene Expression: From Experiments to Data Analysis and Modeling, Cambridge University Press.

Beaucage S.L., Caruthers M.H. (1981) Deoxynucleoside phosphoramidite - a new class of key intermediates for deoxypolynucleotide synthesis. Tetrahedron Lett. 22: 1859-1862.

Beaucage S.L., Iyer R.P. (1992) Advances in the synthesis of oligonucleotides by the phosphoramidite approach. Tetrahedron 48: 2223-2311.

Blalock E.M. (2003) A Beginner's Guide to Microarrays, Kluwer Academic Publishers.

Chiu S.K., Hsu M., Ku W.C., Tu C.Y., Tseng Y.T., Lau W.K., Yan R.Y., Ma J.T., Tzeng C.M. (2003) Synergistic effects of epoxy- and amine-silanes on microarray DNA immobilization and hybridization. Biochem. J. 374(3): 625-632.

Chmielewski M.K., Frydrych E., Uszczyńska B., Ratajczak T., Maciejewski H., Figlerowicz M., Markiewicz W.T. (2011) Sposób wytwarzania mikromacierzy, Patent application P-395147.

Cloarec J.P., Deligianis N., Martin J.R., Laurence I., Souteyrand E., Polychronakos C., Lawrence M.F. (2002) Immobilization of homooligonucleotide probe layers onto $\mathrm{Si} / \mathrm{SiO} 2$ substrates: characterization by electrochemical impedancje measurements and radiolabelling. Biosens. Bioelectron. 17(5): 405-412.

Fiedorow R., Marciniec B., Guliński J., Maciejewski H. (2008) Sposób otrzymywania glicydoksypropylotrialkoksysilanów. Polish Patent. 198548.

Fodor S.P.A., Rava R.P., Huang X.C., Pease A.C., Holmes C.P., Adams C.L. (1993) Multiplexed biochemical assays with biological chips. Nature 364: 555-556.

Fodor S.P.A., Read L., Pirrung M.C., Stryer L., Lu A., Solas D. (1991) Light-directed, spatially addressable parallel chemical synthesis. Science 251: 767-773.

Froehler B.C., Nga P.G., Matteucci M.D. (1986) Synthesis of $D N A$ viadeoxynucleoside $H$-phosphonate intermediates, Nucleic Acids Res. 14: 5399.

Garegg P.J., Regberg T., Stawinski J., Strömberg R. (1985) Formation of internucleotidic bond via phosphonate intermediates. Chem. Scr. 25: 280-282.

Gershon D. 2005. DNA microarrays: more than gene expression. Nature 437: 1195-1198.

Guo Z., Guilfoyle R.A., Thiel A.J., Wang R., Smith L.M. (1994) Direct fluorescence analysis of genetic polymorphisms by hybridization with oligonucleotide arrays on glass supports. Nucl. Acids Res. 22(24): 5456-5465.
Hardiman G. (2003) Microarrays methods and applications: Nuts \& Bolts (The Nuts and Bolts Series), Independent Publishers Group.

Henke L., Krull U.J. (1999) Immobilization technologies used for nucleic acid biosensors: a review. Can. J. Anal. Sci. Spectrosc. 44(2): 62-70.

Horcas I., Fernandez R., Gomez-Rodriguez J.M., Colchero J., Gomez-Herrero J., Baro A.M. (2007) WSXM: A software for scanning probe microscopy and a tool for nanotechnology. Rev. Sci. Instrum. 78: 013705-1-013705-8.

Khandazhinskaya A.L., Kukhanova M.K., Jasko M.V. (2005) New Nonnucleoside Substrates for Terminal Deoxynucleotidyl Transferase: Synthesis and Dependence of Substrate Properties on Structure. Russ. J. Bioorg. Chem. 31(4): 352-356.

Kierzek E., Fratczak A. (2008) Mikromacierze izoenergetyczne, nowa metoda badania struktury i oddzialywań RNA. Biotechnologia 4: 144-153.

Kordek R., Bednarek A.K. (2005) Mikromacierze DNA w badaniach raka piersi. Onkol. Prakt. Klin. 1(1): 10-17.

Lin P., Kong Thoo, Kuksa V.A., Maguire N.M. (1998) The Synthesis of Oxa-Analogues and Homologues of Naturally Occurring Polyamines. Synthesis 6: 859-866.

Luderer F., Walschus U. (2005) Immobilization of oligonucleotides for biochemical sensing by self-assembled monolayers: Thiol-organic bonding on gold and silanization on silica surfaces. Top. Curr. Chem. 260: 37-56.

Luzinov I. et al. (2000) Epoxy-terminated self-assembled monolayers: molecular glues for polymer layers. Langmuir 16: 504-516.

Maciejewski H., Dąbek I., Marciniec B. (2004) Silanowe środki wiążące. Epoksyfunkcyjne karbosilany. Polimery 10: 677687.

Marciniec B., Maciejewski H., Pietraszuk C., Pawluć P., Guliński J. (2011) Encyclopedia of Catalysis. Ed. Horvath I., J. Wiley \& Sons, New York,.

Marciniec B. (2002) Catalysis of hydrosilylation of carboncarbon multiple bonds: Recent Progress. Silicon Chem. 1(3): 155-174.

Metwallib E., Haines D., Becker O., Conzone S., Pantano C.G. (2006) Surface characterizations of mono, di, and triaminosilane treated glass substrates. J. Colloid Interf. Sci. 298: 825-831.

Piehler J., Brecht A., Valiokas R., Liedberg B., Gauglitz G. (2000) A high-density poly(ethylene glycol) polymer brush for immobilization on glass-type surfaces. Biosens. Bioelectron. 15: 473-481.

Pohl E.R., Osterholtz F.D. (1986) Silanes, surfaces and interfaces. Ed. Leyden D. E., Gordon and Breach: New York: 481-500.

Simon R.M. (2004) Design and analysis of DNA microarray investigations (Korn EL and McShane LM. eds), SpringerVerlag.

Trevino V., Falciani F., Barrera-Saldana H.A. (2007) DNA microarrays: a powerful genomic tool for biomedical and clinical research. Mol. Med. 13: 527-541. 
Uszczyńska B., Ratajczak T., Frydrych E., Maciejewski H., Figlerowicz M., Markiewicz W.T., Chmielewski M.K. (2012) The application of click chemistry to the production of DNA microarrays. Lab Chip 12(6): 1151-1156.

Venkatasubbarao S. (2004) Microarrays - status and prospects. Trends Biotechnol. 22: 630-637.

Wong A.K.Y., Krull U.J. (2005) Surface characterization of 3glycidoxypropyltrimethoxysilane films on silicon-based substrates. Anal. Bioanal. Chem. 383: 187-200.

Zhang W., Shmulevich I., Astola J. (2004) Microarray Quality Control, Wiley-Liss.
Zmieńko A., Guzowska-Nowowiejska M., Urbaniak R., Plader W., Formanowicz P., Figlerowicz M. (2011) A tiling microarray for global analysis of chloroplast genome expression in cucumber and other plants. Plant Methods. 7(1), art. no. 29.

Zuker M. (2003) Mfold web server for nucleic acid folding and hybridization prediction. Nucleic Acids Res. 31: 34063415 . 